\title{
T1 mapping in Becker muscular dystrophy patients detects diffuse microfibrosis prior to evidence of late gadolinium enhancement or cardiac dysfunction
}

\author{
Lindsay D Urbinelli $i^{* *}$, Ryan A Moore ${ }^{1}$, Jacob Mathew ${ }^{1}$, James Starc ${ }^{1}$, Mantosh Rattan², John L Jefferies ${ }^{1}$, \\ Michael D Taylor ${ }^{1}$
}

From 19th Annual SCMR Scientific Sessions

Los Angeles, CA, USA. 27-30 January 2016

\section{Background}

Becker muscular dystrophy (BMD) is allelic with Duchenne muscular dystrophy and represents a milder skeletal muscle phenotype; however, cardiac dysfunction remains a significant clinical problem. Cardiac involvement in BMD precedes skeletal muscular decline, and cardiomyopathy often leads to death before the age of 60 years. Cardiac magnetic resonance (CMR) is used for ventricular function assessment and myocardial tissue characterization. Late gadolinium enhancement (LGE) in BMD patients is interpreted as a sign of irreversible macrofibrosis, and often prompts changes in cardiac management to try and limit fibrosis progression. T1 mapping is a more sensitive biomarker of diffuse microfibrosis and may offer an opportunity for earlier therapeutic intervention. Currently, myocardial T1 values in BMD patients are unknown. The purpose of this study is to measure T1 values in BMD patients to determine the prevalence of diffuse myocardial microfibrosis, and its relation to LGE and cardiac dysfunction.

\section{Methods}

Twenty-nine BMD patients (mean age $15 \pm 5$ years; range 8-33 years) underwent CMR for assessment of ventricular function and gadolinium-based tissue characterization. Native myocardial T1 time and post-contrast myocardial $\mathrm{T} 1$ ratios (myocardial T1/blood pool T1) were analyzed and compared to published normal values. Additionally, native $\mathrm{T} 1$ values and post-contrast

'Pediatric Cardiology, Cincinnati Children's Hospital, Cincinnati, OH, USA Full list of author information is available at the end of the article myocardial T1 ratios were compared between BMD patients with and without LGE.

\section{Results}

Mean native T1 values were significantly prolonged in BMD patients compared to published normal values $(1049 \pm 64 \mathrm{msec}$ vs. $953 \pm 23 \mathrm{msec} ; \mathrm{p}=<0.001)$. In addition, the post-contrast T1 ratio (myocardial T1/ blood pool T1) was significantly decreased in BMD patients compared to published normal values $(1.37+/$ 0.32 vs $1.78+/-0.10, \mathrm{p} \leq 0.001)$. Approximately $31 \%$ of BMD patients were positive for LGE, with the basal and mid-ventricular inferolateral segments being the most commonly involved. In BMD patients without LGE, native $\mathrm{T} 1$ times remained significantly prolonged and post-contrast $\mathrm{T} 1$ ratios remained significantly decreased ( $\mathrm{p} \leq 0.001$ for both). Despite the universally abnormal T1 values, only $14 \%$ of BMD patients had evidence of LV dysfunction with an ejection fraction $<55 \%$. Extracellular volumes (ECV) based on T1 mapping results were unable to be calculated due to lack of patient hematocrit data in relation to date of scan.

\section{Conclusions}

T1 mapping in BMD patients demonstrated abnormal pre- and post-contrast $\mathrm{T} 1$ values suggesting diffuse myocardial fibrosis and was a more sensitive marker of fibrosis compared to LGE. Detecting diffuse microfibrosis prior to development of scar and cardiac dysfunction could allow for earlier antifibrosis treatment initiation, which might improve cardiovascular morbidity and mortality in the muscular dystrophy population. 


\section{Authors' details}

${ }^{1}$ Pediatric Cardiology, Cincinnati Children's Hospital, Cincinnati, OH, USA.

${ }^{2}$ Radiology, Cincinnati Children's Hospital, Cincinnati, OH, USA.

Published: 27 January 2016

doi:10.1186/1532-429X-18-S1-P261

Cite this article as: Urbinelli et al: T1 mapping in Becker muscular dystrophy patients detects diffuse microfibrosis prior to evidence of late gadolinium enhancement or cardiac dysfunction. Journal of Cardiovascular Magnetic Resonance 2016 18(Suppl 1):P261.

Submit your next manuscript to BioMed Central and take full advantage of:

- Convenient online submission

- Thorough peer review

- No space constraints or color figure charges

- Immediate publication on acceptance

- Inclusion in PubMed, CAS, Scopus and Google Scholar

- Research which is freely available for redistribution

Submit your manuscript at www.biomedcentral.com/submit
() Biomed Central 